\title{
Mechanism and Application of Static Fracturing Technology on Deep Working Face
}

\author{
Feng Cui, ${ }^{1,2,3}$ Zhaoyuan Lei $\mathbb{D}^{1,2,4}$ Xiaoqiang Cheng, ${ }^{1,5}$ Xueming Wu, ${ }^{6}$ Pengfei Shan $\mathbb{D},{ }^{1,2}$ \\ and Zhaohai $\mathbf{L v}^{7}$ \\ ${ }^{1}$ Energy School, Xi'an University of Science and Technology, Xi'an, Shaanxi 710054, China \\ ${ }^{2}$ Key Laboratory of Western Mines and Hazard Prevention of China Ministry of Education, \\ Xi'an University of Science and Technology, Xi'an, Shaanxi 710054, China \\ ${ }^{3}$ Key Laboratory of Coal Resources Exploration and Comprehensive Utilization, Ministry of Natural Resources, Xi'an, \\ Shaanxi 710021, China \\ ${ }^{4}$ Huangling Mining Group Co. Ltd., Huangling, Shaanxi 727307, China \\ ${ }^{5}$ CCTEG Shenyang Research Institute, Liaoning, Shenyang 11308, China \\ ${ }^{6}$ Shaanxi Coal and Chemical Technology Institute Co. Ltd., Xi'an, Shaanxi 710065, China \\ ${ }^{7}$ Ningxia Mine of CHN Energy Investment Group Co. Ltd., Yinchuan, Ningxia 750004, China \\ Correspondence should be addressed to Zhaoyuan Lei; zhaoyuan125_lei@163.com
}

Received 20 February 2021; Accepted 26 April 2021; Published 13 May 2021

Academic Editor: Xianjie Hao

Copyright (c) 2021 Feng Cui et al. This is an open access article distributed under the Creative Commons Attribution License, which permits unrestricted use, distribution, and reproduction in any medium, provided the original work is properly cited.

\begin{abstract}
Static fracturing technology uses chemical expansion agents to fracture roofs. With the aim of fracturing corner roofs on deep working faces, in this study, the static fracturing technology was investigated through theoretical analysis, laboratory experiments, numerical calculations, and field practice. The theoretical analysis and experiments demonstrated that the swelling force increased with a decrease in the fracturing hole spacing, and the optimal water-cement ratio was 0.33 . Twelve groups of FLAC3D models were designed using SPSSAU. The results revealed that the optimal fracturing effect was achieved when the hole diameter was $60 \mathrm{~mm}$, hole spacing was $40 \mathrm{~cm}$, and hole depth was $6 \mathrm{~m}$. The fracturing effect of hard corner roofs was monitored by peering into the borehole and evaluating the support resistance. Thus, it can be concluded that within the fracturing range, internal fissures in the rock stratum are developed and linked to each other. The support pressure was the highest, $7 \mathrm{~h}$ after grouting, with a value of approximately $26.1 \mathrm{MPa}$, and then decreased gradually to $17.58 \mathrm{MPa}$, indicating that the static fracturing technology attained the expected results.
\end{abstract}

\section{Introduction}

The shifting of working faces results in the formation of a "large space" structure inside the overburden, which can easily cause the roof to hang at the corners of the working face. Affected by the roof depth and plate hardness, a hanging roof may cause an increase in the supporting pressure of the working face, gas accumulation, and stress concentration of coal pillars, resulting in potential hazards for mining [1-3]. The conventional materials used in mining are explosives and water, which can also create hazards in mines. Therefore, the most pressing task is to identify a new type of fracturing material. In addition, research on hard roof fracturing technology is of immense significance for the improvement of the working face environment and for safe and green mining production.

China is rich in coal, and the conditions of each mine are considerably different. Different fracturing technologies, such as hydraulic fracturing $[4,5]$, blasting fracturing $[6,7]$, and $\mathrm{CO}_{2}$ presplitting [8], are used on a case-by-case basis and achieved highly desirable results. A static cracking agent, also known as a chemical expansive agent, is a nonexplosive, 
noncombustible, and nontoxic powdered chemical mixture with high expansion performance. Tanaka was the first to perform a volumetric expansion experiment using the oxidation processes of $\mathrm{CaO}$ and $\mathrm{H}_{2} \mathrm{O}$ in concrete fracturing [9]. After long-term development, Chinese experts have developed mixing materials for the expansive agent and have studied the factors that affect the fracturing effect [10-12]. Early Chinese research on expansive agent fracturing was mainly applied to the cutting of rock materials [13]. With the significant challenges caused by the deep mining of coal resources $[14,15]$, by exploring the high ground stress, high ground temperature, high water pressure, and strong production disturbance in the deep courses [16, 17], experts worldwide have analysed the large deformation of deep rock and features of the unloading failure zone of the arch form $[18,19]$ and development characteristics of fractures $[20,21]$ and have determined the energy characteristics and criteria for the impact of depth on lithomechanical behaviour and dynamic instability [22-24]. Despite long-term research and practice, few studies have been conducted on the application of static fracturing technology in mines and adjoining rock control. Furthermore, research has been conducted on the prevention and control of deep dynamic disasters [25-28]. Considering the relatively low reaction speed and environmentally friendly characteristics of static crushing agents, combined with deep adjoining rock control, static fracturing technology for hard roofs in deep working faces has been introduced.

To realise the safe, green, and efficient control of the hard roofs of deep working faces, in this study, an experiment was conducted by fracturing a roof at a corner. Static fracturing technology was used, and factors affecting the expansion effect were determined through theoretical analysis and laboratory tests. In addition, the fracturing parameters suitable for a mine were obtained, in combination with the affecting factors, and SPSSAU was used to design a numerical calculation scheme. Finally, the effect of applying the static fracturing technology was verified on a working site.

\section{Project Background}

2.1. Overview of Mine and Working Face Production. The roof structures of the Binchang, Huangling, and Weibei mining areas in Shaanxi Province are considerably different. However, their uniaxial compressive strengths are generally greater than $45 \mathrm{MPa}$. In addition, a mine owned by Shaanxi Coal and Chemical Industry Group Co., Ltd., with an approved production capacity of $2 \mathrm{Mt} / \mathrm{a}$, is the main production unit of the group. It mainly mines at the No. 2 coal seam, which is within the Yan'an Formation of the middle Jurassic period, with an inclination angle of $1-5^{\circ}$. The coal seam ranges from stable to more stable, and the mine has a high gas content. The No. 21209 working face is 395-699 m deep and is adjacent to the No. 21207 gob in the southwest and the No. 21211 working face in the northeast. The rest of the coal seam is unmined. The surface elevation of the working face is $+1175 \mathrm{~m}$ to $+1424 \mathrm{~m}$, and the underground elevation is $+723 \mathrm{~m}$ to $+784 \mathrm{~m}$. The ground surface is covered with medium and low mountain forests, with no buildings and other facilities around the mine. Figure 1 depicts the location of the No. 21209 working face and the overburden characteristics.

For the No. 21209 working face, the designed strike length was approximately $1235 \mathrm{~m}$, incline length was approximately $153 \mathrm{~m}$, and average coal thickness was $1.1 \mathrm{~m}$. The dimensions (width $\times$ height) of the air inlet and return roadways were $4.6 \times 3.8$ and $5.4 \times 3.6 \mathrm{~m}$, respectively. The coal mining method used was strike longwall retreat fullseam mining. The roof of the gob was treated using a fully caving method. Table 1 lists the characteristics of the adjoining rock in the No. 21209 working face. Lithomechanical experiments demonstrated that the natural compressive strength of the roof and coal seam floor of the No. 21209 working face was $38.6-57.5 \mathrm{MPa}$, predominantly in the range of $42.3-50.8 \mathrm{MPa}$, and the single shear strength was generally 4.22-6.4 MPa.

2.2. General Conditions of Mine. With the continuous alternation of the working face and the incomplete collapse of the adjacent working face, the roof of the working face is continuous and forms a "large space" structure inside the overburden with the collapse space. With the backstopping of the working face, the scale of the extraction area increases. The large space structure inside the overburden is easy to cause the stage stress failure of roof plate at the corner of working face, and the length of the overhanging roof at the upper corner is larger than that at the lower corner. With varying degrees of mining along the gob, it is easy to cause stage stress failure in the roof at the corners of the working face, and the suspended roof length of the upper corner is greater than that of the lower corner. As the working face continues to advance with the strike, the corner roof extends to the gob and flexes $(\omega)$. When the flexing of the roof reaches the bending limit, the roof at the corner collapses. The long-term suspended roof at the corner causes severe deformation of the adjoining rock of the two roadways, which can easily increase the support pressure of the working face, gas accumulation, and stress concentration of the coal pillar, gradually producing different strata behaviours (see Figure 2).

\section{Mechanism of Static Fracturing Technology}

3.1. Mechanism of Static Fracturing Rock Mass. Static fracturing is a chemical reaction that occurs after a chemical expansive agent is mixed with water, which can increase the reaction volume and heat. The expansive agent is a mixture mainly composed of $\mathrm{CaO}, \mathrm{Ca}_{3} \mathrm{SiO}_{3}$, and $\mathrm{MgO}$. The chemical equation is shown in

$$
\mathrm{CaO}+\mathrm{H}_{2} \mathrm{O}=\mathrm{Ca}(\mathrm{OH})_{2}+\mathrm{Q} .
$$

During the hydration reaction process of the chemical expansive agent, there are two volumetric model structures, i.e., free state and constrained state, as depicted in Figure 3. In the free state, the molecular structure is uniformly arranged and only expands in volume, without causing swelling pressure. If it is spatially constrained, the molecules 
are squeezed together, reducing the porosity. It expands instantly in a limited space and generates swelling pressure. If the swelling pressure is greater than the ultimate tensile strength of the constraint, the development of the internal fracture of the object accelerates until it bursts completely.

Constrained by the rock mass, the volumetric expansion produced by the hydration reaction process acts on the constraint. The expansive agent is also under an acting force with the same magnitude but opposite direction. The shape change process of the chemical expansive agent is based on rheology and elastic strain. Affected by the extremely small modulus of elasticity of the hardened solid formed after the hydration reaction of the chemical expansive agent, the swelling pressure generated by the chemical expansive agent under the restraint is caused by the elastic strain alone. In other words, as the proportion of elastic strain that accounts for the total strain increases, the rate of increase of the swelling pressure increases, and the effect of swelling and fracturing improves. In addition, the tensile stress inside the rock mass increases with the continuously increasing swelling pressure. When the ultimate tensile strength at the filling hole wall on the pivoting face is reached, several radial rupturing fissures appear. With the continuous increase in the swelling force, the fissures continue to develop until they are linked to each other, forming a continuous rupturing surface until the swelling and fracturing are completed.

3.2. Mechanical Mechanism of Static Fracturing. In static fracturing, a large swelling force generated by the volumetric expansion of the chemical expansive agent in the hydration reaction causes the constraint to reach the ultimate tensile strength and then rupture. When there exist multiple free faces of the constraint, the tensile stress generated by the volumetric expansion of the chemical expansive agent causes rock mass failure. In addition, rupturing fissures generally develop from the edge of the hole bottom to the free face. In general, porous swelling and fracturing technologies are adopted. Considering double-hole swelling and fracturing as an example, the effects of the physical and mechanical action are illustrated in Figure 4.

Assuming that there are two circular holes on an infinite elastomer under internal pressure, the acting effect of the two holes can be approximately regarded as the superposition of the respective effects on the elastomer.

$$
\begin{aligned}
& \sigma_{r}=\sigma_{r 1}+\sigma_{r 2}=-\left(\frac{r_{1}^{2}}{r_{2}^{2}} q_{1}(t)+\frac{r_{2}^{2}}{(l-r)^{2}} q_{2}(t)\right), \\
& \sigma_{\theta}=\sigma_{\theta 1}+\sigma_{\theta 2}=\frac{r_{1}^{2}}{r_{2}^{2}} q_{1}(t)+\frac{r_{2}^{2}}{(l-r)^{2}} q_{2}(t) .
\end{aligned}
$$

Then,

$$
\sigma=\left|\sigma_{2}-\sigma_{\theta}\right|=\frac{2 r_{1}^{2}}{r^{2}} q_{1}(t)+\frac{2 r_{2}^{2}}{(l-r)^{2}} q_{2}(t) .
$$

From (3), by obtaining the reciprocal of $r$ and equating it to zero, the following is obtained:

$$
r=\frac{1}{\left\{1+\sqrt[3]{r_{2}^{2} q_{2}(t)} /\left[r_{1}^{2} q_{1}(t)\right]\right\}}
$$
is

This point denotes the stress at the extreme point, which

$\sigma=\left[1+\sqrt[3]{\frac{r_{2}^{2} q_{2}(t)}{r_{1}^{2} q_{1}(t)}}\right]^{2}\left[\frac{2 r_{1}^{2} q_{1}(t)}{l^{2}}+\frac{2 r_{2}^{2} q_{2}(t)}{\sqrt[3]{r_{2}^{2} q_{2}(t) / r_{1}^{2} q_{1}(t)}}\right]$.

If the left boundary $r=r_{1}$,

$$
\sigma_{\text {Left }}=2 q_{1}(t)+\frac{2 r_{2}^{2}}{\left(l-r_{1}\right)^{2}} q_{2}(t)
$$

If the right boundary $r=l-r_{2}$,

$$
\sigma_{\text {Right }}=2 q_{2}(t)+\frac{2 r_{1}^{2}}{\left(l-r_{2}\right)^{2}} q_{1}(t) .
$$

Then, the minimum stress on the line connecting the centres of the two holes $\mathrm{O}_{1}$ and $\mathrm{O}_{2}$ is

$$
\sigma_{\min }=\min \left\{\sigma, \sigma_{\text {Left }}, \sigma_{\text {Right }}\right\} \text {. }
$$

In engineering practices, it is generally considered that the blasting hole and explosives used are the same, and the difference in the charging time is ignored; i.e., when $r=r_{1}=r_{2}, q=q_{1}=q_{2}$.

$$
\sigma_{\min } \frac{8 r q}{(l+2 r)^{2}}
$$

According to the maximum principal shear stress theory, the crushing medium must meet the condition

$$
\sigma_{\min } \geq[\sigma]
$$

i.e.,

$$
q \geq \frac{(l+2 r)^{2}}{8 r^{2}}[\sigma]
$$

where $[\sigma]$ is the ultimate tensile strength of the crushing medium.

Therefore, a higher stress can be generated when the hole spacing is as short as possible. If holes are equally spaced, then the compressive and tensile stresses are at their maximum.

\section{Determination of Physical and Mechanical Parameters of Expansive Agent}

The swelling force originates from the volumetric expansion caused by the hydration reaction. By comparing the volumetric expansion characteristics under different water-cement ratio conditions, the optimal range of the water-cement ratio is determined. Three indicators-swelling volume, swelling force, and temperature generated by the hydration reaction of the static fracturing of the rock stratum-are used as the basis for determining the parameters of the expansive agent. 


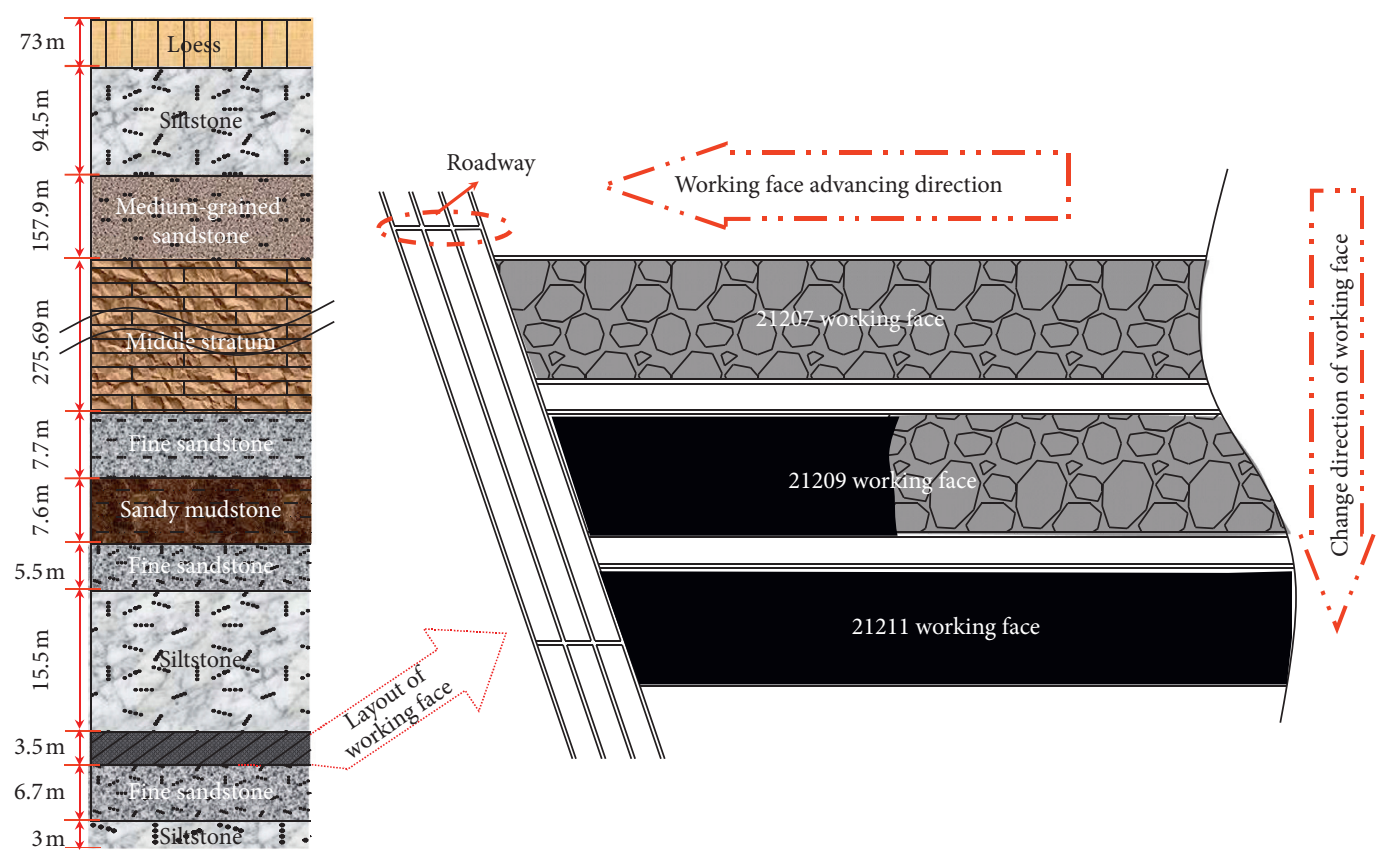

FIgURE 1: Occurrence characteristics of No. 21209 working face.

TABLE 1: Characteristics of adjoining rock on roof and floor of No. 21209 working face.

\begin{tabular}{|c|c|c|c|}
\hline Description & Rock name & $\begin{array}{c}\text { Thickness } \\
(\mathrm{m})\end{array}$ & Lithologic characteristic \\
\hline Upper roof & Fine sandstone & $5.5-7.1$ & $\begin{array}{l}\text { Varies greatly in thickness, mainly quartz and feldspar, argillaceous cementation, } \\
\text { with wavy bedding, rock Protodyakonov hardness } f=4-6\end{array}$ \\
\hline $\begin{array}{l}\text { Immediate } \\
\text { roof }\end{array}$ & Medium sandstone & $2-4$ & $\begin{array}{l}\text { Grey to greyish white, dominated by quartz, containing thin layers of } \\
\text { micropsammite, argillaceous cement, thin-layered, plate-like bedding, containing } \\
\text { plant fossils and mica flakes, rock Protodyakonov hardness } f=6-7\end{array}$ \\
\hline 2\# coal & Coal & $1.0-1.5$ & $\begin{array}{l}\text { Mainly semibright to semidull coal, with thin layers of dull coal, massive structure, } \\
\text { developed endogenetic fracture in coal, and containing dirt bands in the lower part of } \\
\text { the coal seam }\end{array}$ \\
\hline Floor & $\begin{array}{l}\text { Micropsammite } \\
\text { siltstone }\end{array}$ & $1-7.3$ & $\begin{array}{l}\text { The rock compositions are mainly quartz and feldspar, thin layered, containing plant } \\
\text { fossil fragments and mica sheets, horizontal stratification or not showing } \\
\text { stratification, the thickness being about } 1 \text { to } 7.3 \text { meters, and the rock hardness } f=4-6\end{array}$ \\
\hline
\end{tabular}

4.1. Expansion Characteristics under Different Water-Cement Ratios. Uniformly graduated cylinders $(500 \mathrm{ml})$ were prepared. The chemical expansive agent was mixed according to the four water-cement ratios, and they were stirred until no blocky particles were found. The expansion characteristics of the expansive agent with four different water-cement ratios are presented in Table 2. To ensure the reliability of the test, the test was performed in a room with a temperature change range of less than $2^{\circ} \mathrm{C}$. The purified water required for the test was placed in the laboratory for $24 \mathrm{~h}$ in advance to ensure that the initial water temperature was consistent with the room temperature.

In the initial state, the slurry with a water-cement ratio of $1: 1$ to $1: 3$ exhibited good fluidity. At a water-cement ratio of $1: 4$, the fluidity was evidently insufficient, and the resistance during mixing was higher. After being rested for approximately $10 \mathrm{~min}$, the slurry exhibited stratification. After continually being rested for 20 minutes, the surface of the sediment gradually dried and started to solidify. With regard to the horizontal swelling characteristics, the cracking became increasingly varied with the increase in the watercement ratio. In addition, the surface of the $1: 1$ slurry dried and no longer changed after solidification; the 1:2 slurry began to bulge in the process and exhibited obvious cracking. The 1:3 slurry cracked gently, and the block became larger. The 1:4 slurry was too dense, and beaker expanded and cracked, making it impossible to observe the volumetric shape after expansion.

With regard to the vertical expansion characteristics, the expansive volume varied significantly with the increase in the water-cement ratio. The $1: 3$ slurry exhibited a maximum volumetric expansion of approximately $290 \%$, of which the volume expanded by nearly three times. The 1:4 slurry demonstrated a volumetric expansion rate of $250 \%$. Therefore, the optimal water-cement ratio was determined to be between $1: 3$ and $1: 4$. 


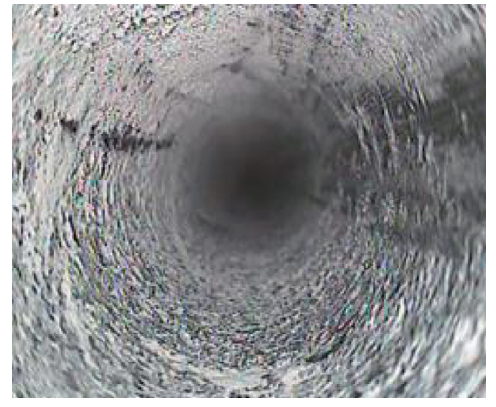

(a)

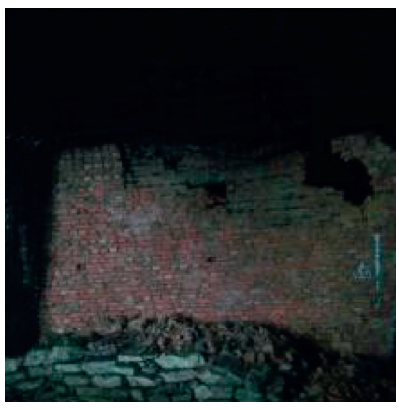

(b)

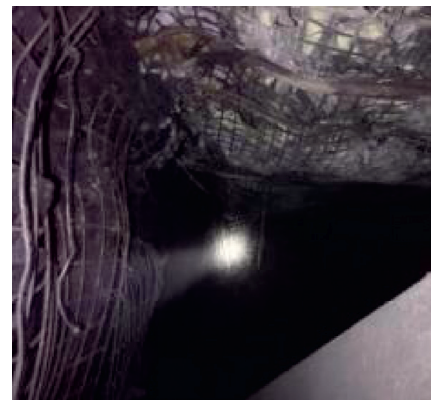

(c)

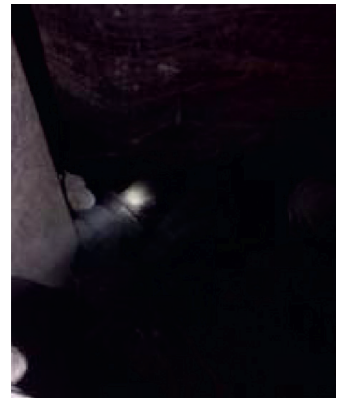

(d)

FIGURE 2: Strata behaviours: (a) internal conditions of the corner roof, (b) deformed enclosed wall, (c) suspended roof at the upper corner, and (d) bending and sinking lower corner.

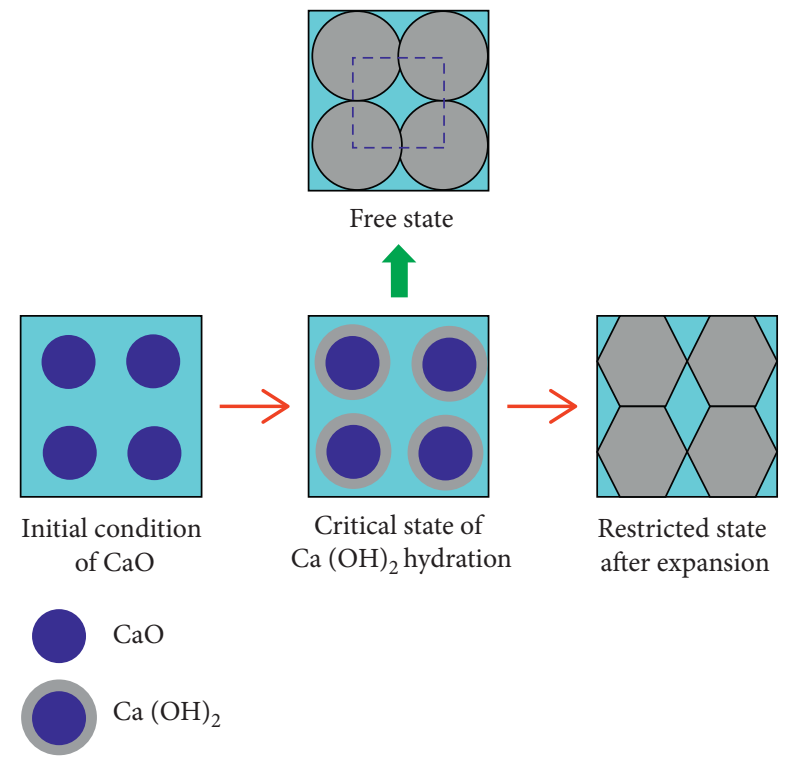

FiguRE 3: Molecular model structure after chemical reaction of expansive agent.

4.2. Determination of Mechanical Properties of Expansive Agent. The optimal water-cement ratio of $1: 3$ to $1: 4$ was further categorised into five different cases, i.e., 0.25, 0.29, $0.33,0.37$, and 0.41 , to monitor the swelling force mechanical behaviour to obtain the superior water-cement ratio, as depicted in Figure 5. Five different slurries were stirred and filled into uniform steel pipes for strain monitoring. The specifications of the steel pipes are listed in Table 3.

A temperature sensor and strain tester were used to monitor the strain of the steel pipes in real time during the reaction process until the strain and temperature of the steel pipes stabilised. The temperature and swelling force change curves of the expansive agent are illustrated in Figures 6 and 7 .

The entire temperature change process with different water-cement ratios basically tended to stabilise after $4 \mathrm{~h}$, as depicted in Figure 6. The high temperature generated was approximately $180^{\circ} \mathrm{C}$, which was considerably lesser than the ignition point of coal and, thus, could cause the spontaneous combustion of the coal bed. The maximum temperature decreased as the water-cement ratio increased. The maximum temperature was $184.8^{\circ} \mathrm{C}$, and the minimum temperature was $144.6^{\circ} \mathrm{C}$. Therefore, as the content of the expansive agent increased, the temperature generated during the hydration reaction also increased.

Figure 7 depicts the characteristics of the swelling force changes under the five water-cement ratio conditions with a hole diameter of $40 \mathrm{~mm}$. For the water-cement ratios of 0.41 , $0.37,0.33,0.29$, and 0.25 , the generated swelling forces were $25.50,28.24,39.14,32.81$, and $30.01 \mathrm{MPa}$, respectively. Therefore, the maximum swelling force was generated when the water-cement ratio was 0.33 .

4.3. Mechanical Effect of Hole Diameter on Swelling Force. The generated swelling force varied with different explosive loads of various hole diameters. To further explore the influence of different hole diameters on the swelling force, the water-cement material that generated the largest swelling force was filled into pipes with hole diameters of $30,36,40$, 45 , and $60 \mathrm{~mm}$ to measure the swelling forces.

The swelling characteristics of five hole diameters after $700 \mathrm{~min}$ of continuous monitoring are depicted in Figure 8. The swelling force of each hole diameter reached its 


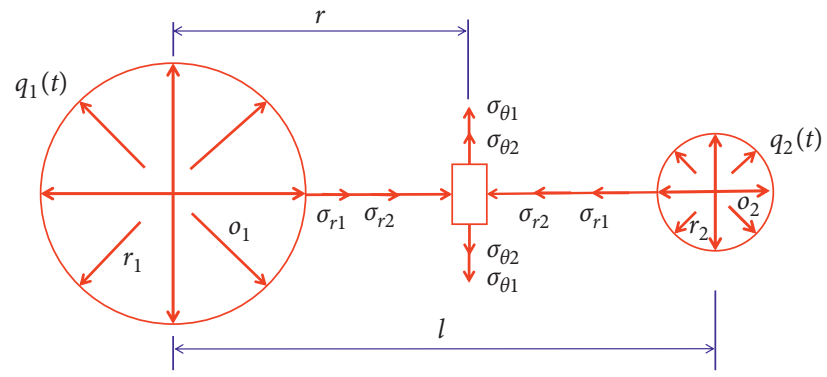

FIGURE 4: Mechanical model of double-hole swelling and fracturing: $O_{1}$ is charging hole 1 , and $O_{2}$ is charging hole 2.

maximum and stabilised within $275 \mathrm{~min}$. As the hole diameter increased, the time taken to reach the maximum swelling force decreased, and the corresponding swelling force increased. The maximum swelling forces for diameters of $30,36,40,45$, and $60 \mathrm{~mm}$ were $39.14,52.24,60.33,68.44$, and $74.12 \mathrm{MPa}$, respectively. The distribution characteristics of the maximum swelling forces of five hole diameters are depicted in Figure 9.

Thus, within the range of experimental testing, the hole diameter range is directly proportional to the hole diameter. According to the distribution characteristics of the hole diameter and swelling force, the fitting formula is shown in (12) and the degree of fitting $\left(R_{2}\right)$ is approximately 0.9987.

$$
y=-0.472 x^{2}+5.477 x-83.079 \text {. }
$$

Therefore, if the hole diameter is $53.28 \mathrm{~mm}$, the maximum swelling force is $72.57 \mathrm{MPa}$. After the hole diameter is increased to 53.28, the swelling force reduces with increasing hole diameter.

As a result, if the optimal water-cement ratio is 0.33 , the swelling force is at its maximum when the hole diameter is $53.28 \mathrm{~mm}$.

\section{Determination of Static Fracturing Technical Parameters}

5.1. Determination of Experimental Program. According to the actual production situation on-site, it was determined that the hole diameters were 42,50 , and $60 \mathrm{~mm}$, the hole spacings were $40,50,60,70$, and $80 \mathrm{~cm}$, and the hole depths were $2,4,6$, and $8 \mathrm{~m}$. The three factors (hole diameter, hole spacing, and hole depth) and levels were input into the orthogonal design software SPSSAU. Twelve sets of experimental programs were obtained, as presented in Table 4.

5.2. FLAC3D Modelling. According to the site conditions, combined with the orthogonal design experiments, the swelling and fracturing effects were studied with different hole diameters, depths, and spacings. The FLAC3D model of double-hole fracturing was established, as illustrated in Figure 10. The dimensions of the design model were $2 \times 2 \mathrm{~m}$. The depth $(H)$ varied with the hole depth designed by the orthogonal experiment. Here, $R_{1}$ and $R_{2}$ denote the diameters of the two holes, and $L$ denotes the hole spacing. Three indicators, the plastic zone width $(\Delta L)$, plastic zone volume
$(\Delta V)$, and swelling stress $(\Delta U)$ among the holes, were determined, and the swelling and fracturing effects of each model were analysed.

A $0.5-\mathrm{MPa}$ stress was applied in the $x$ - and $z$-directions of the model to simulate the actual adjoining rock stress. Through comprehensive analysis of the stress, plastic zone, etc., perpendicular to the direction of the connecting line of the bores, the swelling and fracturing effect of each hole were determined, and the optimal parameters of the holes were determined. The roof parameters of the numerical computation are listed in Table 5.

At the beginning of the simulation, a radial stress with a water-cement ratio of 0.33 was applied to the inside of different hole diameters to simulate the swelling stress. According to fitting formula in (11), the obtained swelling forces corresponding to 42, 50, and $60 \mathrm{~mm}$ were 63.78, 71.39, and $74.12 \mathrm{MPa}$, respectively.

5.3. Distribution Characteristics of Swelling and Fracturing Stress. The fissures generated after the rock stratum was fractured, evolved along the two holes in a linear fashion. The stress disturbance characteristics of the five parameters obtained from the 42, 50, and $60 \mathrm{~mm}$ holes were similar, as depicted in Figure 11.

With the same hole diameter, the stress is greater at each hole and lowest on the outside of the hole, generally presenting a "double hump" distribution characteristic. The corresponding stress peak shifts toward both sides with increased spacing between the holes. In addition, the stress peak decreases gradually during the shift. A comparison of the stresses of different parameters with the three hole diameters reveals that the stress disturbance caused by the fracturing is the highest when the hole diameter is $60 \mathrm{~mm}$ and is relatively high when the hole spacing is $50 \mathrm{~mm}$.

\subsection{Plastic Failure Characteristics of Swelling and Fracturing.}

The swelling and fracturing of the three hole parameters caused plastic damage to the rock stratum, as presented in Table 6.

The fracturing effect is jointly affected by the hole diameter and hole spacing. The plastic failure range increases with increasing hole diameter and reduces with increasing hole spacing. When the hole diameter is $42 \mathrm{~mm}$ and the hole spacing is $40 \mathrm{~cm}$, the plastic failure is linked by a width of approximately $1.09 \mathrm{~m}$, and the failure characteristic presents 
TABLE 2: Expansion characteristics of expansive agent with different water-cement ratios.

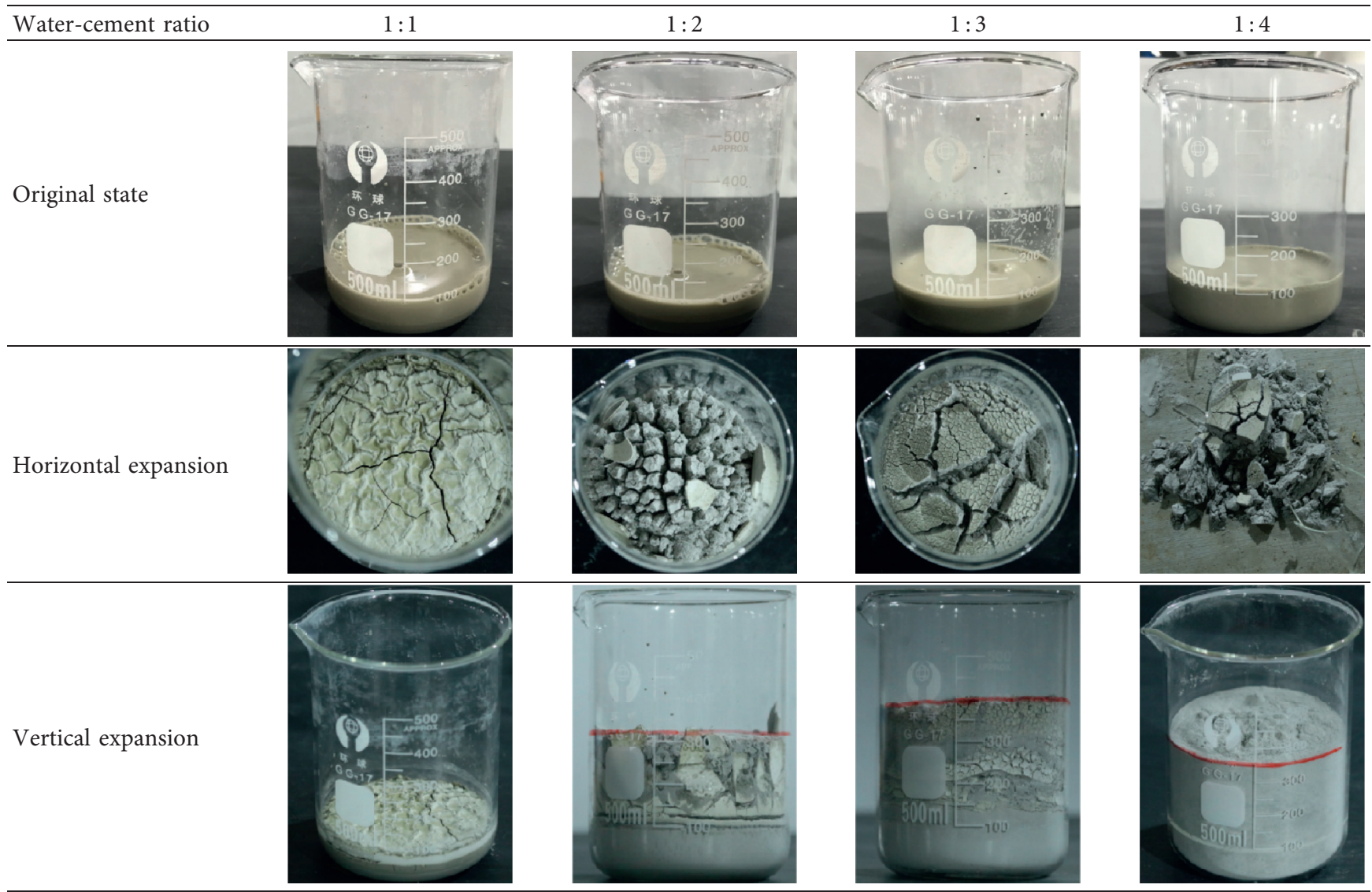

a " $\infty$ " shape. As the hole spacing increases, the plastic failure range is abruptly reduced and not linked. With the increase in hole diameter, if the hole spacing is $40 \mathrm{~cm}$, the plastic zone is linked and continuously expands to the periphery of the hole. For the other hole spacing, the plastic failure range gradually reduces with the increase in the hole spacing.

Therefore, under static fracturing, the fissures of the hole develop with a divergent shape. The swelling force increases with the increase in the hole diameter. The failure characteristic is the most obvious when the hole spacing is $40 \mathrm{~cm}$.

5.5. Influencing Factors of SPSSAU on Fracturing. According to the numerical simulation computed by SPSSAU, the three evaluation indicators $(\Delta U, \Delta L$, and $\Delta V)$ are presented in Table 7 . As theoretically analysed, the range results of the three indicators were obtained. The range expression is shown in (13). As the range increases, the influence of the changed level of a certain factor on the test indicator also increases.

$$
\max \left\{k_{1}, k_{2}, k_{3}, k_{4}\right\}-\min \left\{k_{1}, k_{2}, k_{3}, k_{4}\right\} .
$$

5.5.1. Analysis of Stress Peak $\Delta U$. The range of the tested stress peak $\Delta \mathrm{U}$ is presented in Table 8 . The inspection results of the three factors revealed the following order: factor $\mathrm{A}$ (hole diameter) $>$ factor $\mathrm{B}$ (hole spacing) $>$ factor $\mathrm{C}$ (hole depth) with the smallest range. This indicates that the bore diameter demonstrates the most significant influence on the model stress, followed by hole spacing and, finally, hole depth. Considering that as the stress applied on the rock mass increases, the fracturing effect improves, the optimal combination is determined as A3B1C3-that is, the optimal effect can be obtained with a hole diameter of $60 \mathrm{~mm}$, hole spacing of $40 \mathrm{~cm}$, and hole depth of $6 \mathrm{~m}$.

5.5.2. Analysing Width of Plastic Zone $(\Delta L)$. The ranges of each influencing factor on the width of the plastic zone $(\Delta L)$ are $0.52,1.416667$, and 0.4 , respectively, as presented in Table 9. Evidently, factor B demonstrates the most significant influence on the experimental indicators. Therefore, factor B (hole spacing) is the main consideration, followed by factor A (hole diameter) and finally factor C (hole depth). The greater the width of the plastic zone is, the more easily the swelling and fracturing lines link to each other. Therefore, the optimal combination is A3B1C2-that is, the optimal effect can be obtained with a hole diameter of $60 \mathrm{~mm}$, hole spacing of $40 \mathrm{~cm}$, and hole depth of $4 \mathrm{~m}$.

5.5.3. Analysing Volume of Plastic Zone $\Delta U$. The influence of each influencing factor on the volume of the plastic zone $\Delta U$ is presented in Table 10. The range of the three factors can be arranged as follows: $\mathrm{B}>\mathrm{C}>\mathrm{A}$. Therefore, hole spacing has the most significant influence. The influence of the hole 


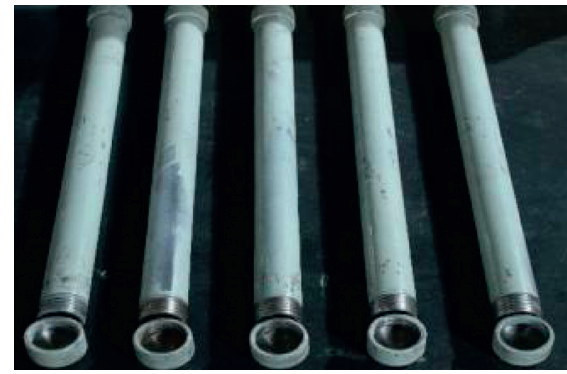

(a)

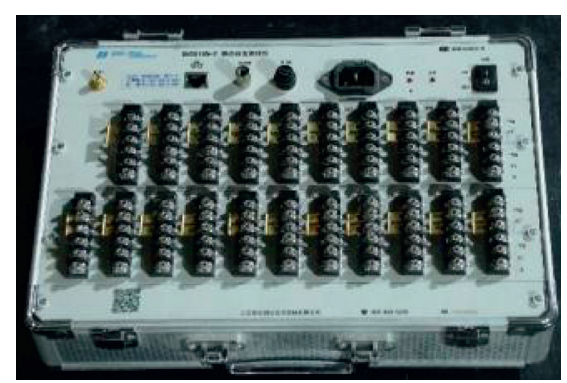

(b)

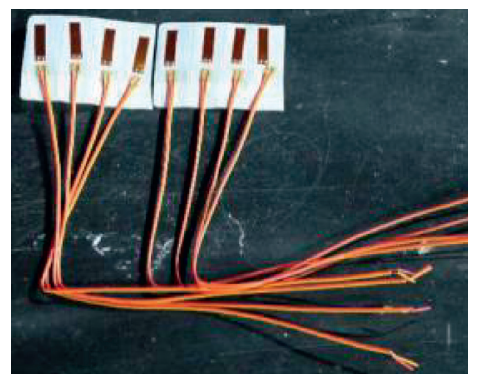

(c)

FIGURE 5: Instruments and equipment required for swelling force testing experiment: (a) 304 stainless steel pipe, (b) swelling force tester, and (c) resistance strain piece.

TABLE 3: Specifications of experimental steel pipes.

\begin{tabular}{lcccccc}
\hline Model of steel pipes & Length $(\mathrm{mm})$ & I.D. $(\mathrm{mm})$ & O.D. $(\mathrm{mm})$ & Wall thickness $(\mathrm{mm})$ & Elastic modulus $(\mathrm{GPa})$ & Poisson's ratio \\
\hline 304 stainless steel & 500 & 40 & 48 & 4 & 206 & 0.3 \\
\hline
\end{tabular}

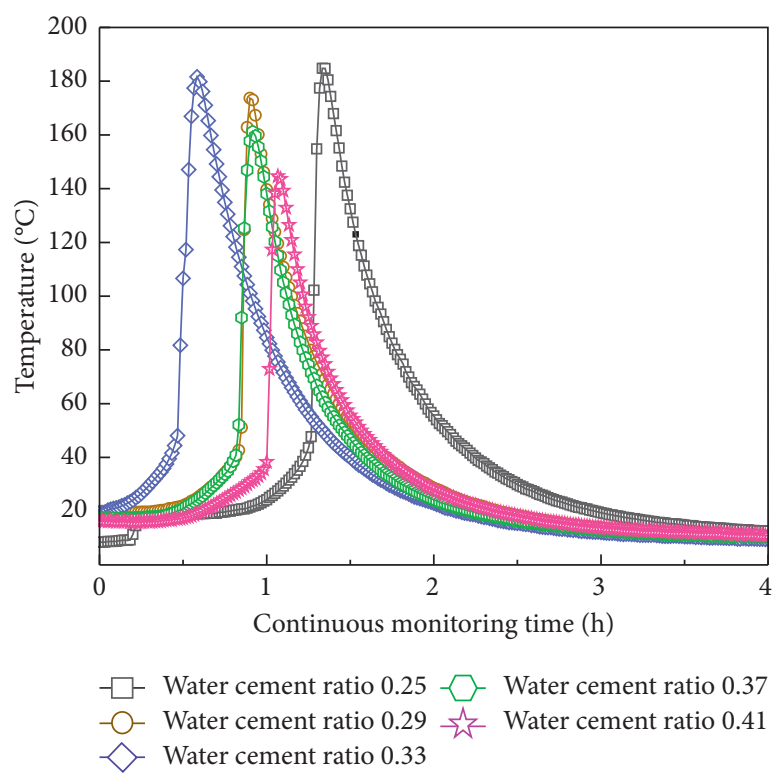

Figure 6: Temperature change characteristics at various water-cement ratios.

diameter is slightly lesser than that of the hole depth. Therefore, under the conditions of these evaluation indicators, the optimal combination is $\mathrm{A} 3 \mathrm{~B} 1 \mathrm{C} 3$ - that is, the optimal effect can be obtained with a hole diameter of $60 \mathrm{~mm}$, hole spacing of $40 \mathrm{~cm}$, and hole depth of $6 \mathrm{~m}$.

5.6. Determination of Optimal Parameters. Twelve static fracturing cases performed using the SPSSAU orthogonal design software reveal that the swelling stress applied around the hole is significantly increased with an increase in the fracturing hole diameter. As the hole spacing decreases, the width and volume of the plastic zone increase. Tables 7-9 indicate that the three factors that influence the fracturing effect have their respective results, with hole spacing exhibiting the most significant influence. The hole depth also affects the volume range of the plastic zone. Therefore, the optimal hole parameters for swelling and fracturing were preliminarily obtained, a hole diameter of $60 \mathrm{~mm}$, hole spacing of $40 \mathrm{~cm}$, and hole depth of $6 \mathrm{~m}$.

\section{Engineering Practice}

6.1. Static Fracturing Construction Scheme and Process. On No. 21209 working face, the average daily suspended roof area of the corner roof was approximately $10 \times 3.5 \mathrm{~m}$. Therefore, swelling and fracturing construction was performed in two grooves along the working face. The construction process is illustrated in Figure 12. The expansive 


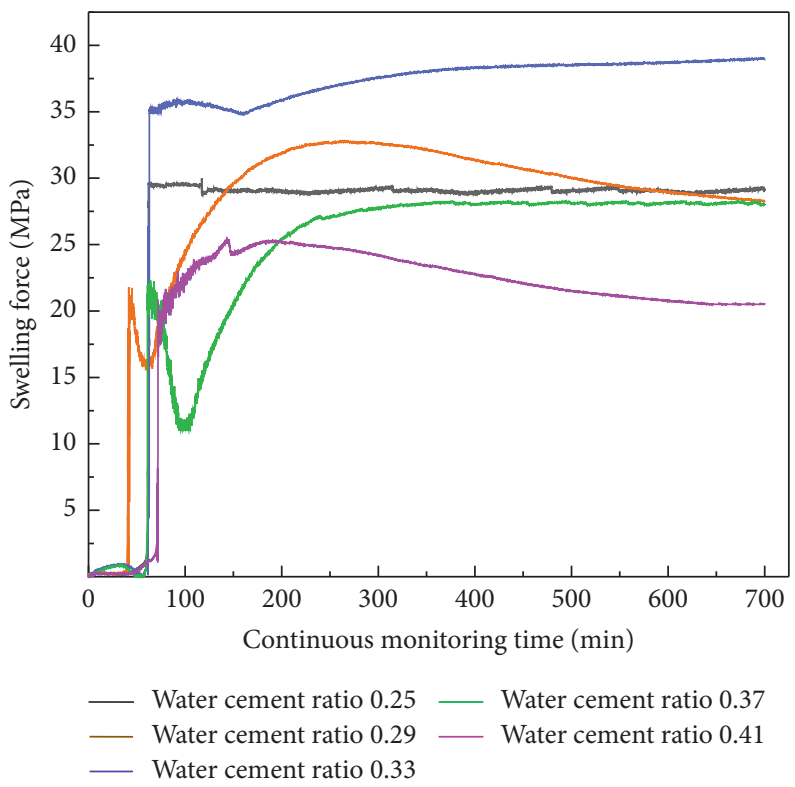

FIGURE 7: Swelling force change characteristics at various water-cement ratios.

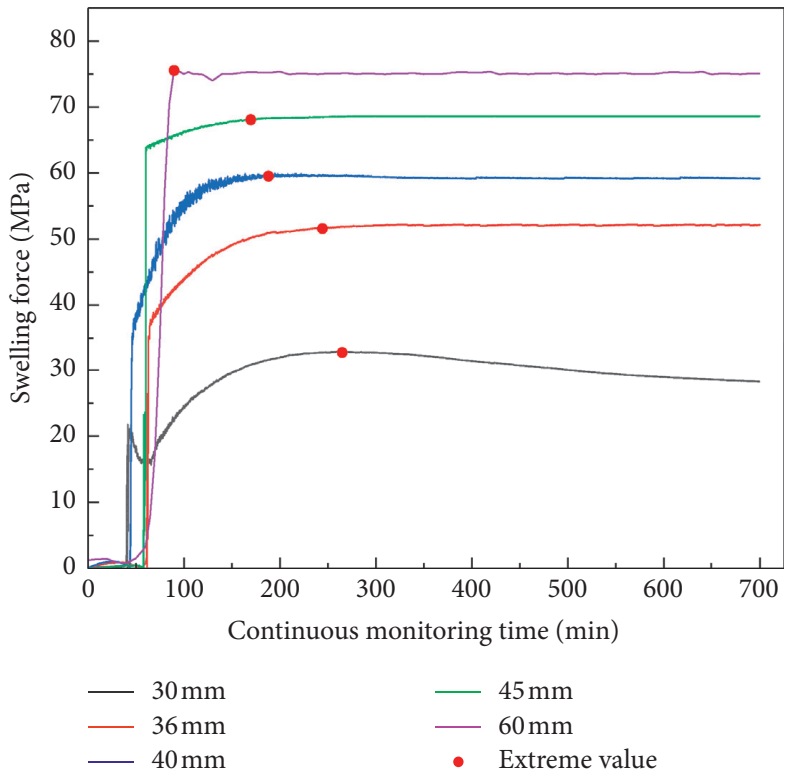

FIgURE 8: Swelling characteristics of five hole diameters.

agent and water were mixed at a mixing ratio of 0.33 and then injected into the fracturing hole with a grouting pump after stirring.

According to the width of the two roadways of the working face, 10 and 12 roof-cutting holes were designed, respectively. Two roadways of $50 \mathrm{~m}$ were placed in front of the working face for roof cutting. The expansive agent and water were mixed at a mixing ratio of 0.33 . Considering the belt roadway as an example, the site construction scheme is illustrated in Figure 13.

The top of the roadway was designed with roof-cutting holes $0.5 \mathrm{~m}$ from both pit slopes. The remaining hole spacing was $0.4 \mathrm{~m}$, hole length was $6 \mathrm{~m}$, and inclination toward the gob was approximately $10^{\circ}$. The grouting liquid was directly injected into the hole using a grouting pump. To ensure the fracturing effect, a mine hole packer was used to seal the hole. The on-site grouting construction process is depicted in Figure 14.

6.2. Testing Fracturing Effect. Twenty-four hours after static fracturing, three monitoring methods, i.e., peering into the hole, evaluating the pressure distribution of the advanced support, and examining the bed separation of the roof, were adopted to analyse the effect on the physical and mechanical characteristics of the roof fracturing. 


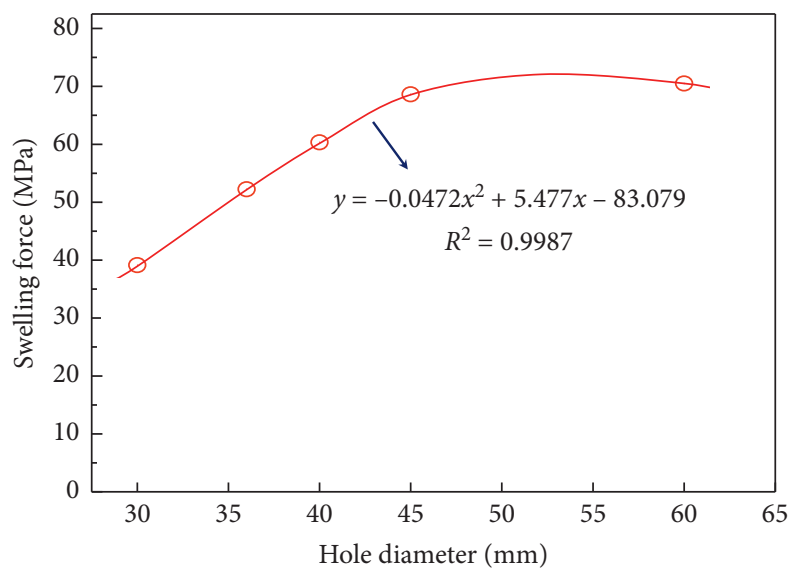

FIgURE 9: Relationship of hole diameter and swelling force.

TABle 4: Orthogonal test program.

\begin{tabular}{lccc}
\hline Serial number & & $\begin{array}{c}\text { Factor } \\
\text { Hole spacing B }(\mathrm{cm})\end{array}$ & Hole depth C (m) \\
\hline 1 & Hole diameter A $(\mathrm{mm})$ & 40 & 2 \\
2 & 42 & 50 & 4 \\
3 & 42 & 60 & 6 \\
4 & 42 & 70 & 4 \\
5 & 42 & 40 & 6 \\
6 & 50 & 50 & 8 \\
7 & 50 & 60 & 2 \\
8 & 50 & 80 & 6 \\
9 & 50 & 40 & 8 \\
10 & 60 & 50 & 2 \\
11 & 60 & 70 & 4 \\
12 & 60 & 80 & \\
\hline
\end{tabular}

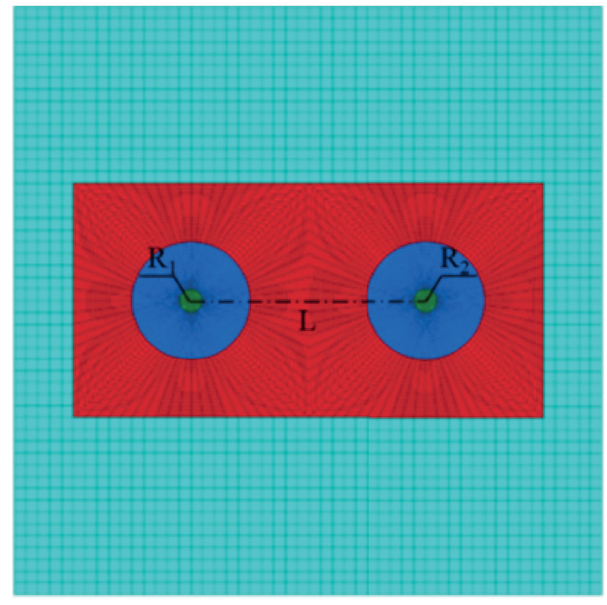

(a)

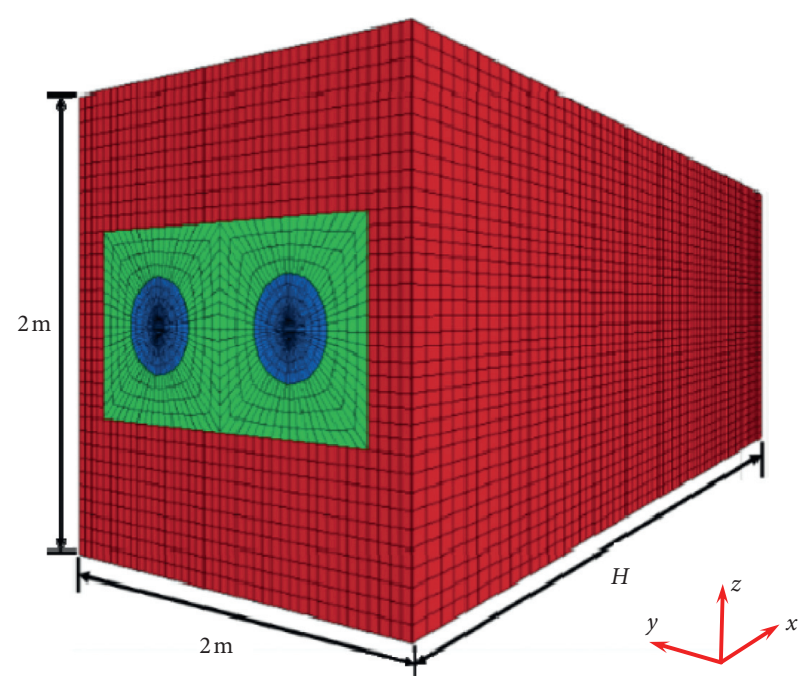

(b)

Figure 10: FLAC3D calculation and design model.

TABle 5: Numerical simulation of physical parameters.

\begin{tabular}{lccccccc}
\hline Lithology & $\begin{array}{c}\text { Density } \\
\left(\mathrm{kg} / \mathrm{m}^{3}\right)\end{array}$ & $\begin{array}{c}\text { Bulk modulus } \\
(\mathrm{GPa})\end{array}$ & $\begin{array}{c}\text { Shear modulus } \\
(\mathrm{GPa})\end{array}$ & $\begin{array}{c}\text { Internal friction } \\
\text { angle }\left({ }^{\circ}\right)\end{array}$ & $\begin{array}{c}\text { Cohesion } \\
(\mathrm{MPa})\end{array}$ & $\begin{array}{c}\text { Tensile strength } \\
(\mathrm{MPa})\end{array}$ & $\begin{array}{c}\text { Compressive strength } \\
(\mathrm{MPa})\end{array}$ \\
\hline Siltstone & 2650 & 1.86 & 1.12 & 27 & 4.20 & 3.50 & 55.78 \\
\hline
\end{tabular}




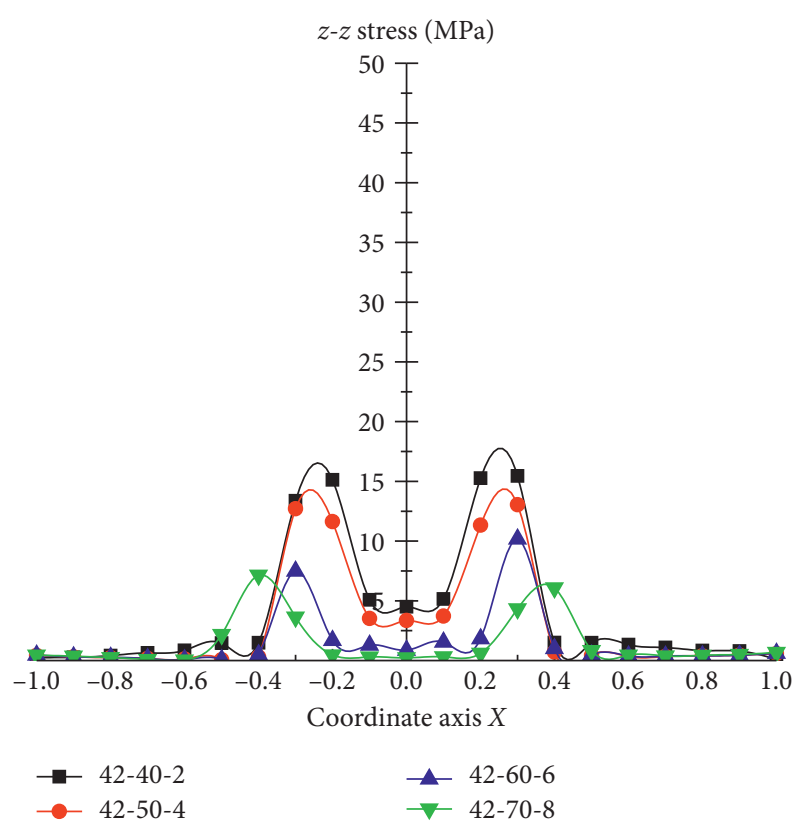

(a)

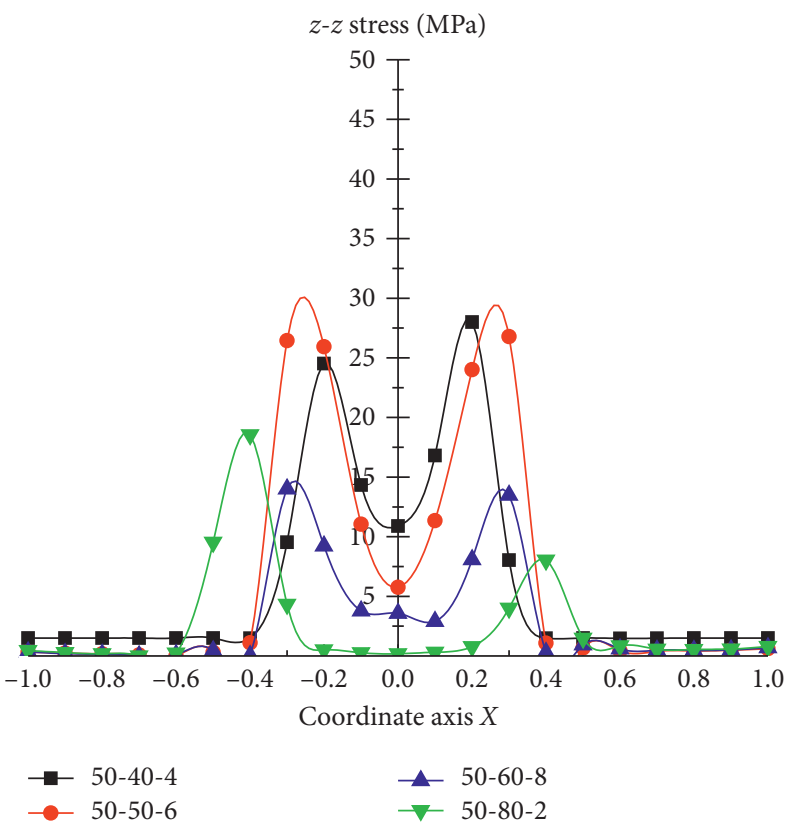

(b)

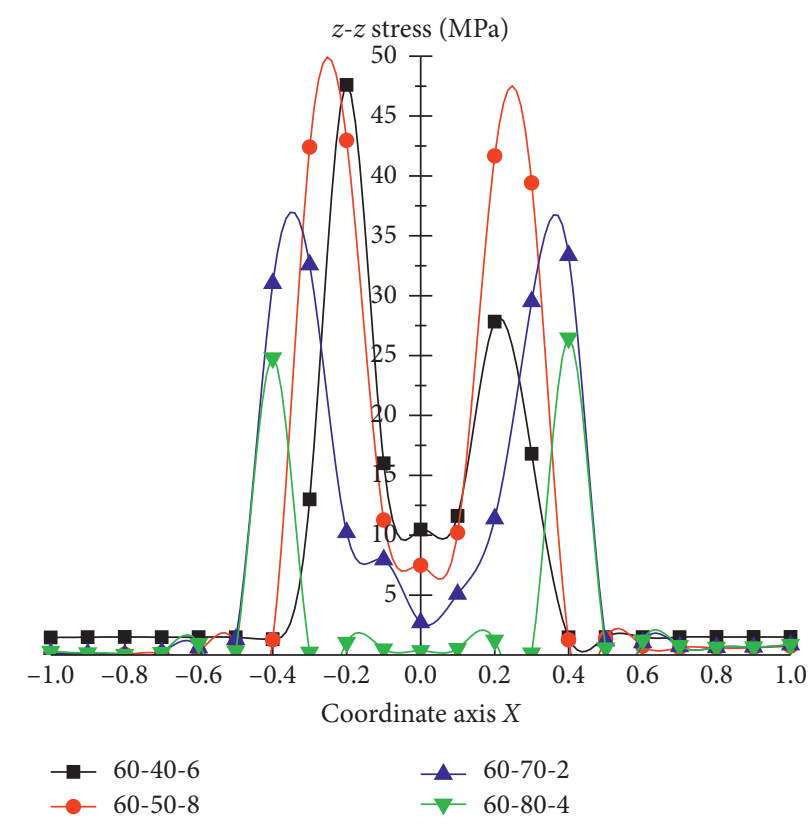

(c)

Figure 11: $Z-Z$ stress distribution along connecting line of holes: (a) 42, (b) 50, and (c) $60 \mathrm{~mm}$ hole diameter.

6.2.1. Physical Detection of Fracturing Effect. After static fracturing, detection was conducted within $0.4 \mathrm{~m}$ of the roof fracturing range. The fracturing effect is illustrated in Figure 15.

The fracturing inside the roof is depicted in Figure 15(a). The roof was blocky 0.5 and $1.5 \mathrm{~m}$ toward the inside. The fissure at $2.5 \mathrm{~m}$ was obviously expanded, and some blocks were present. The roof at 3.5-5.5 m exhibited bed separation and was partially blocky. In the entire fracturing range, the integrity of the roof was broken, and the fracture evolution became faster. The entire roof bottom was broken, as depicted in Figure 15(b). The roof was bending to the side of the gob and caving, and the rock mass was further broken into several larger rock blocks.

6.2.2. Distribution of Support Pressure. The support pressure conditions under the original state and static fracturing conditions were imposed at the same position of the belt roadway of the working face for two days, and they were continuously monitored for $12 \mathrm{~h}$. The distribution characteristics of the support pressure are depicted in Figure 16. 
TABLE 6: Distribution of plastic zones.

\begin{tabular}{|c|c|c|c|c|}
\hline Model & $42-40-2$ & $42-50-4$ & $42-60-6$ & $42-70-8$ \\
\hline Width of plastic zone $(\mathrm{m})$ & 1.09 & 0.42 & 0.5 & 0.54 \\
\hline Volume of plastic zone $\left(\mathrm{m}^{3}\right)$ & 1.48899 & 0.5323469 & 0.8060281 & 1.255744 \\
\hline Modality of plastic zone & & c. & c & (6) $\%$ \\
\hline Model & $50-40-4$ & $50-50-6$ & $50-60-8$ & $50-80-2$ \\
\hline Width of plastic zone $(\mathrm{m})$ & 2 & 0.62 & 0.61 & 0.62 \\
\hline Volume of plastic zone $\left(\mathrm{m}^{3}\right)$ & 12.489855 & 1.376251 & 1.943232 & 0.4106066 \\
\hline Modality of plastic zone & & $8 \times$ & $4 x$ & 8. \\
\hline Model & $60-40-6$ & $60-50-8$ & $60-70-2$ & $60-80-4$ \\
\hline Width of plastic zone $(\mathrm{m})$ & 2 & 0.91 & 0.88 & 0.84 \\
\hline Volume of plastic zone $\left(\mathrm{m}^{3}\right)$ & 23.558345 & 3.800948 & 0.7876212 & 1.27701 \\
\hline Modality of plastic zone & & $d x+x$ & $x=x$ & \% \\
\hline
\end{tabular}

TABLe 7: Orthogonal test data.

\begin{tabular}{|c|c|c|c|c|c|c|}
\hline \multirow{2}{*}{ Indicators } & \multicolumn{6}{|c|}{ Schemes } \\
\hline & 1 & 2 & 3 & 4 & 5 & 6 \\
\hline Peak stress $\Delta \mathrm{U}(\mathrm{MPa})$ & 15.45 & 13.05 & 10.17 & 7.14 & 28.01 & 26.78 \\
\hline Width of plastic zone $\Delta L(\mathrm{~m})$ & 1.09 & 0.42 & 0.5 & 0.54 & 2 & 0.62 \\
\hline \multirow{2}{*}{ Volume of plastic zone $\Delta \mathrm{V}\left(\mathrm{m}^{3}\right)$} & 1.49 & 0.53 & 0.81 & 1.26 & 12.49 & 1.38 \\
\hline & 7 & 8 & 9 & 10 & 11 & 12 \\
\hline Peak stress $\Delta \mathrm{U}(\mathrm{MPa})$ & 14.00 & 18.54 & 47.60 & 42.97 & 33.36 & 26.46 \\
\hline Width of plastic zone $\Delta L(\mathrm{~m})$ & 0.61 & 0.62 & 2 & 0.91 & 0.88 & 0.84 \\
\hline Volume of plastic zone $\Delta \mathrm{V}\left(\mathrm{m}^{3}\right)$ & 1.94 & 0.41 & 25.33 & 3.48 & 0.72 & 1.21 \\
\hline
\end{tabular}

TABLE 8: Stress $\Delta U$ range of each model.

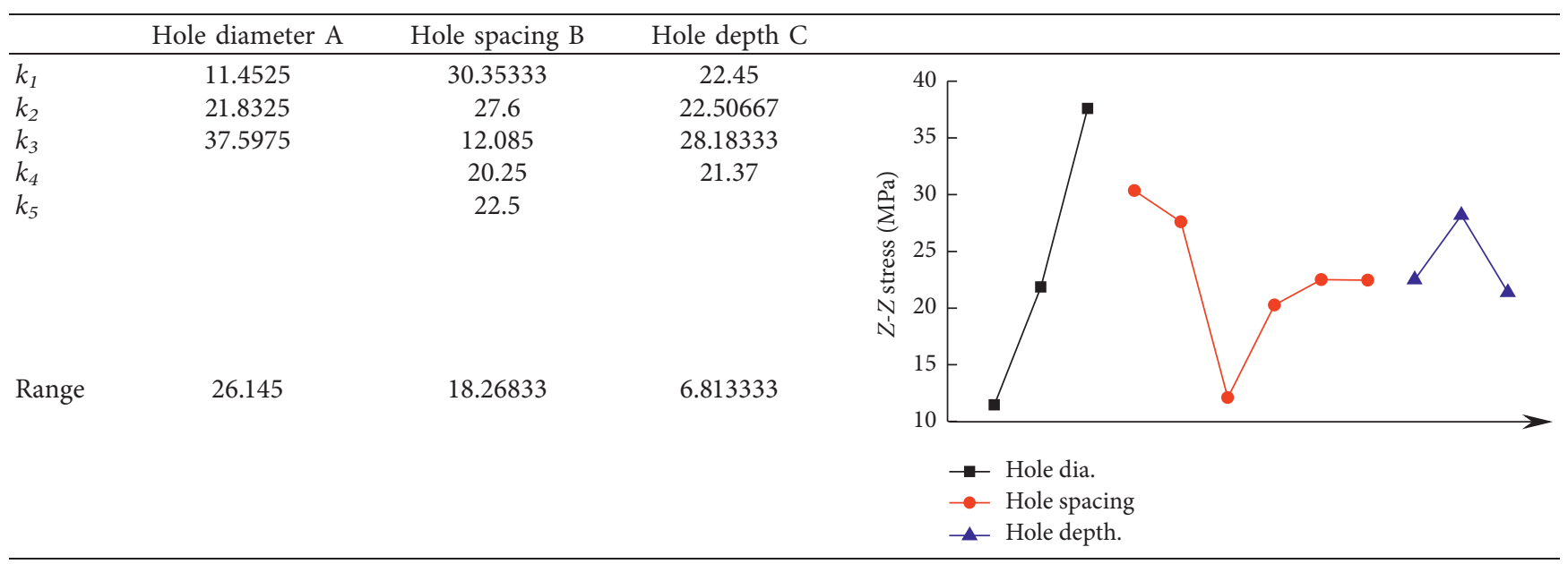


TABLE 9: Range for width of plastic zone $\Delta L$ of each model.

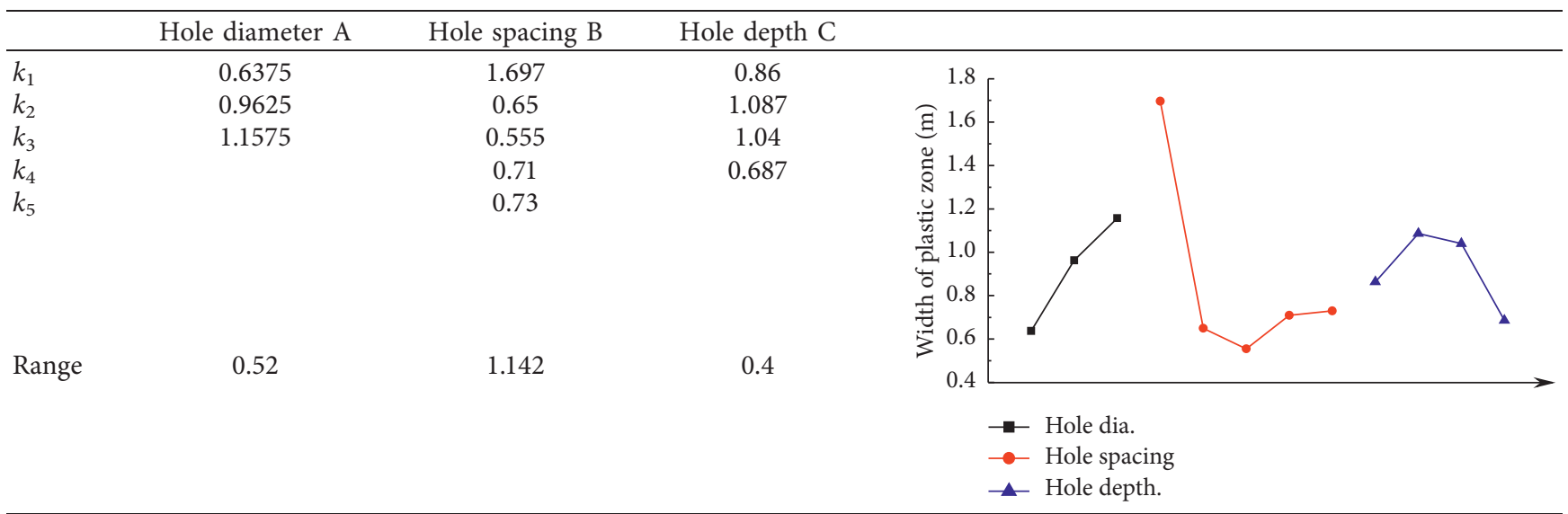

TABLE 10: Range for volume of plastic zone $\Delta U$ of each model.

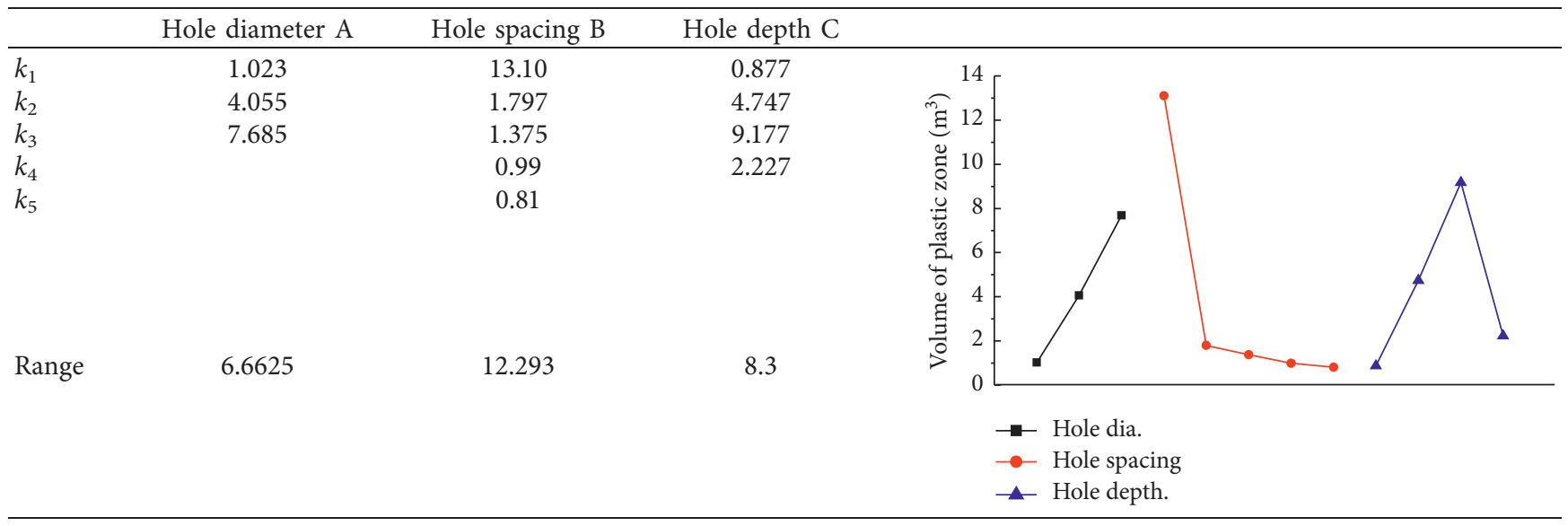

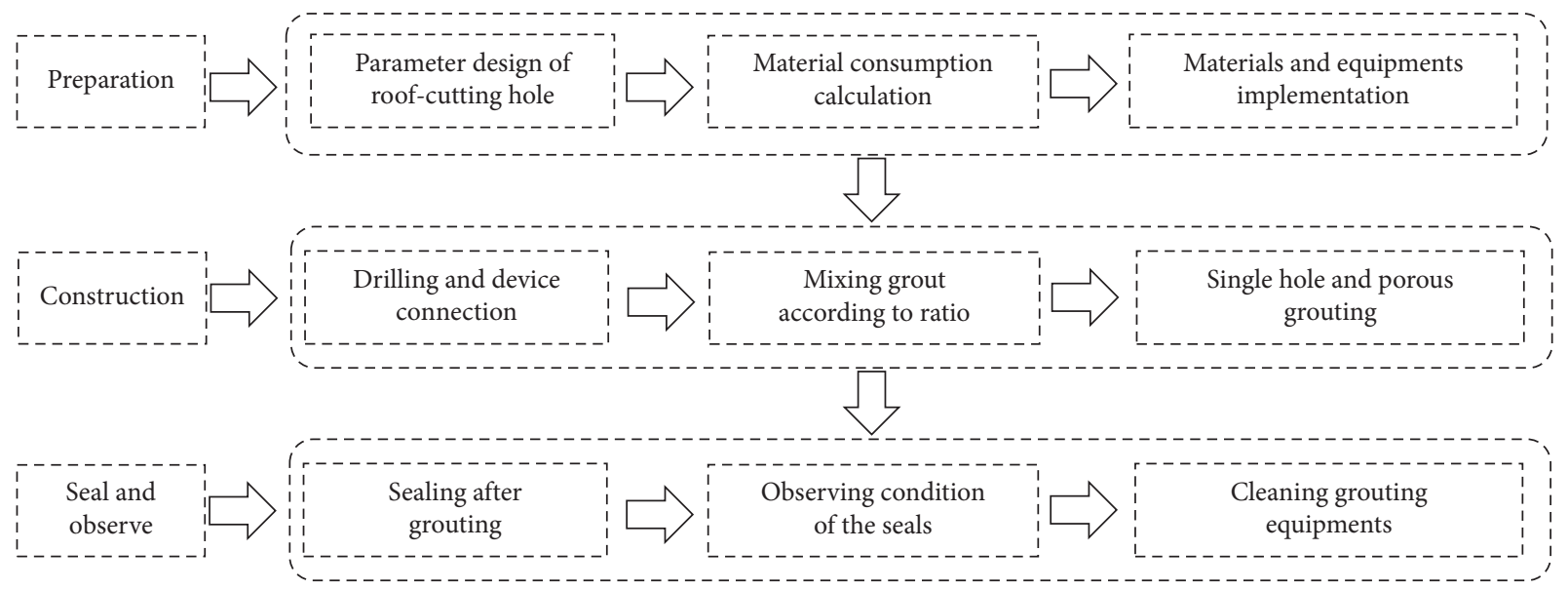

Figure 12: Construction process flow.

In the original state, the working resistance of the support oscillated at approximately $24 \mathrm{MPa}$ and remained stable. Six consecutive hours after static fracturing and grouting, the continuous hydration reaction started to occur. At the seventh hour, the support pressure increased to 26.1 MPa. After $8 \mathrm{~h}$, the pressure decreased to $23 \mathrm{MPa}$. Over 


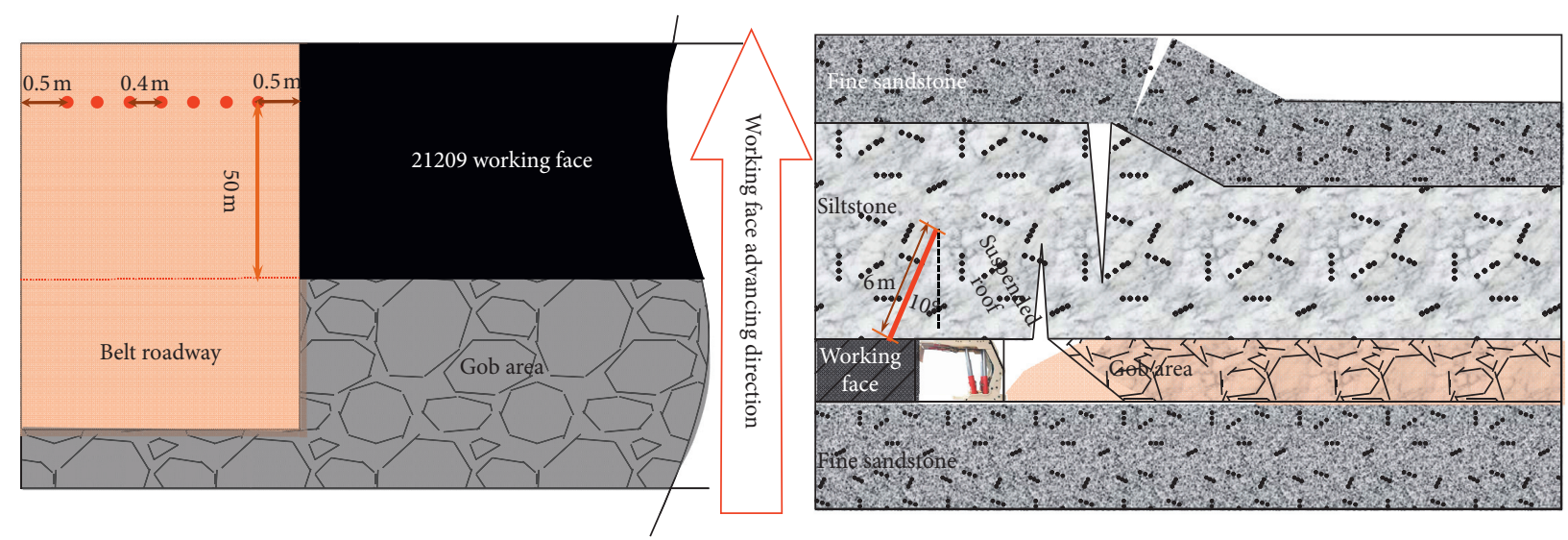

FIGURE 13: Site construction plan. Left: top view of hole arrangement; right: side view of hole arrangement.

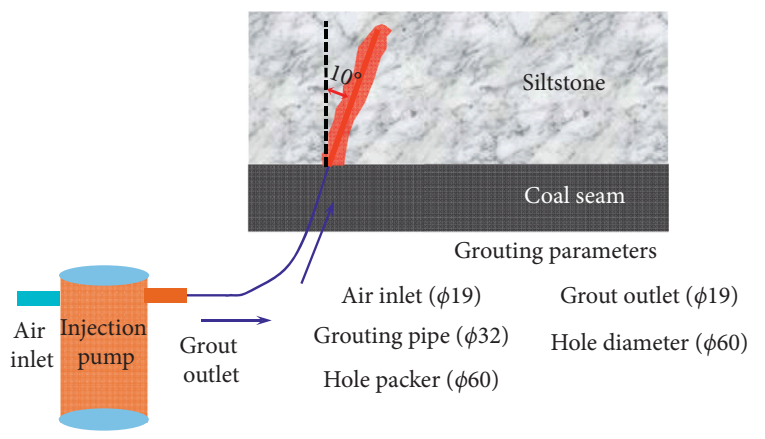

(a)

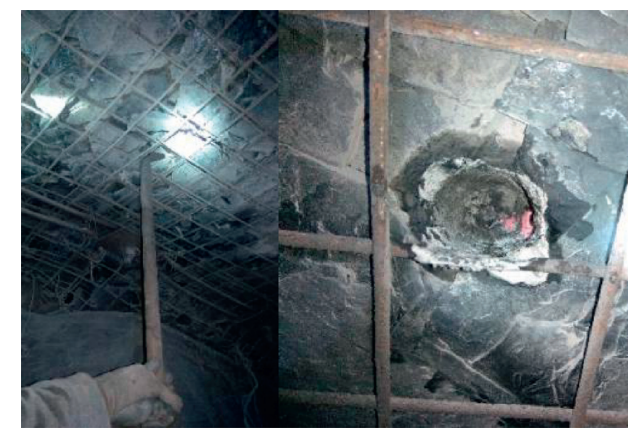

(b)

FIGURE 14: Grouting construction process of No. 21209 working face: (a) on-site grouting process, (b) grouting construction, and (c) hole sealing completed.

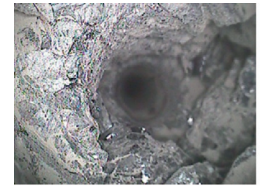

$0.5 \mathrm{~m}$

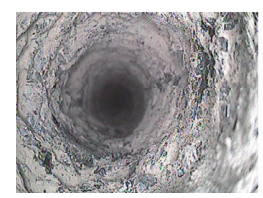

$3.5 \mathrm{~m}$

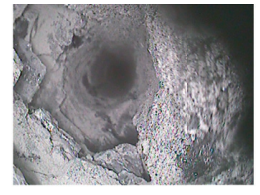

$1.5 \mathrm{~m}$

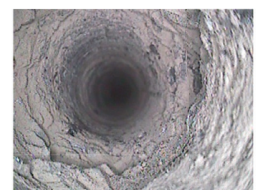

$4.5 \mathrm{~m}$

(a)

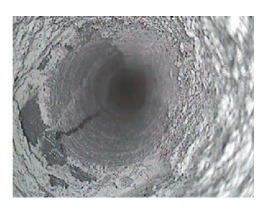

$2.5 \mathrm{~m}$

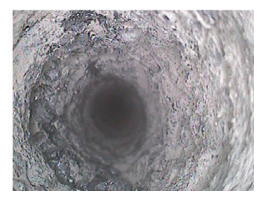

$5.5 \mathrm{~m}$

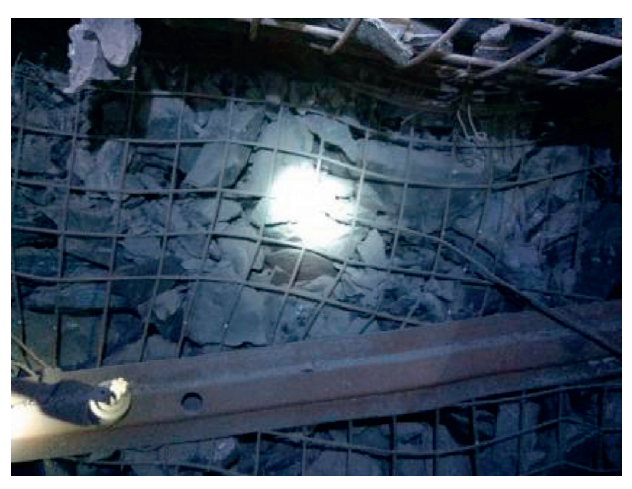

(b)

FIGURE 15: Roof fracturing effect: (a) development of internal fissures within the roof and (b) results of breaking the roof.

time, the support pressure continuously reduced. After $12 \mathrm{~h}$, the support pressure decreased to $17.58 \mathrm{MPa}$. Thus, the corner roof could collapse in time, without causing a suspended roof.
Hence, during the entire process of chemical swelling and fracturing, there is no need to evacuate personnel, and other work processes are not adversely affected, thereby ensuring the continuity and efficiency of mine operations 


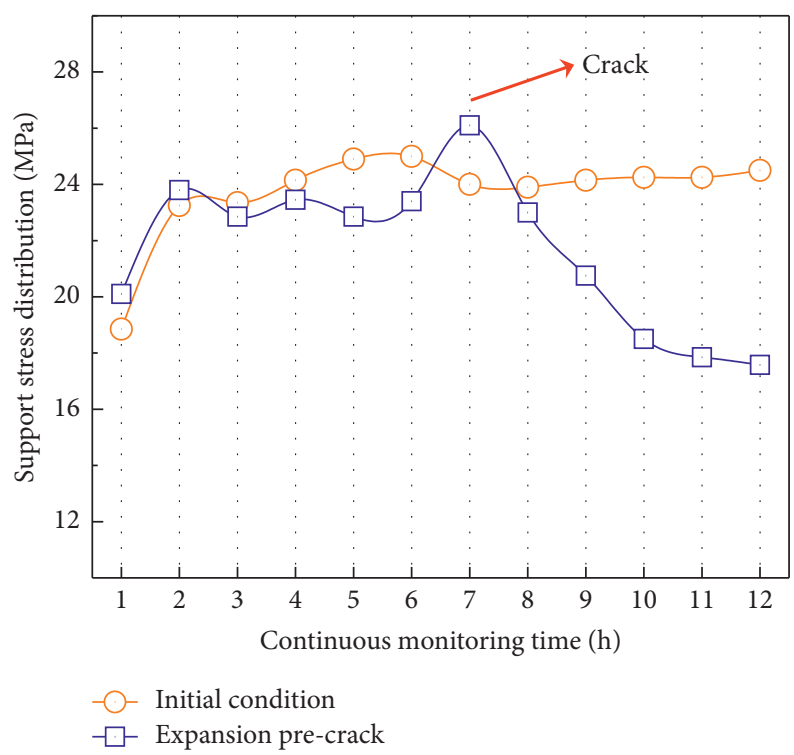

Figure 16: Distribution curve of support pressure.

and improving the operation coefficient of safety.

\section{Conclusions}

(1) Static fracturing technology can increase the swelling force. The relationship between swelling force and fracturing hole spacing was investigated through theoretical analysis. It was concluded that if holes are equally spaced, then the compressive and tensile stresses are at their maximum.

(2) After the expansive agent reacts chemically with water, the maximum swelling force is generated in the same hole if the water-cement ratio is 0.33 . The swelling forces of different hole diameters demonstrate an inverted parabolic distribution characteristic. Fitting the relationship between hole diameter and swelling force demonstrated that the swelling force is the largest with a water-cement ratio of 0.33 and a hole diameter of $53.28 \mathrm{~mm}$.

(3) Twelve experimental cases were designed for three variants-hole diameter, hole depth, and hole spacing - with the SPSSAU orthogonal design software. The stress distribution and plastic failure characteristics under different fracturing conditions were computed using the corresponding FLAC3D numerical values. The optimal static fracturing parameters obtained include a hole diameter of $60 \mathrm{~mm}$, hole spacing of $40 \mathrm{~cm}$, and hole depth of $6 \mathrm{~m}$.

(4) The on-site monitoring results revealed that the hydration reaction occurs after $6 \mathrm{~h}$. The support pressure increases up to $26.1 \mathrm{MPa}$ at the seventh hour and then declines, and the support pressure continuously decreases to $17.58 \mathrm{MPa}$ over time. The internal fissures in the rock stratum within the fracturing range are developed and linked to each other. Thus, the collapse of the corner roof can be achieved in time without causing a suspended roof.

\section{Data Availability}

No data were used to support this study.

\section{Conflicts of Interest}

The authors declare that they have no conflicts of interest.

\section{Acknowledgments}

This work was sponsored by the National Natural Science Foundation of China (grant nos. 51874231 and 51504184), which is part of the Shaanxi Natural Science Fundamental Research Program Enterprise United Fund (grant no. 2019JLZ-04), and the Outstanding Youth Science Fund of the Xi'an University of Science and Technology (grant no. 2019YQ2-16).

\section{References}

[1] Q. Zhang, C.-H. Peng, R.-C. Liu, B.-S. Jiang, and M.-M. Lu, "Analytical solutions for the mechanical behaviors of a hard roof subjected to any form of front abutment pressures," Tunnelling and Underground Space Technology, vol. 85, pp. 128-139, 2019.

[2] F. Cui, C. Jia, and X. P. Lai, "Study on the evolution characteristics and stability of overburden structure inupward mining of short distance coal seams with strong burst tendency," Chinese Journal of Rock Mechanics and Engineering, vol. 39, no. 3, pp. 507-521, 2020.

[3] L. M. Dou and W. Q. He, Theory and Technology of Rock Burst Prevention, China University of Mining and Technology Press, Xuzhou, China, 2001.

[4] B. X. Huang, C. Y. Liu, and J. H. Fu, "Hydraulic fracturing after water pressure control blasting for increased fracturing," International Journal of Rock Mechanics and Mining Sciences, vol. 6, no. 4, pp. 976-983, 2011.

[5] B.-X. Huang, B. Yu, F. Feng, Z. Li, Y.-Z. Wang, and J.-R. Liu, "Field investigation into directional hydraulic fracturing for 
hard roof in Tashan coal mine," Journal of Coal Science and Engineering (China), vol. 19, no. 2, pp. 153-159, 2013.

[6] F. Wang, S. Tu, Y. Yuan, Y. Feng, F. Chen, and H. Tu, "Deephole pre-split blasting mechanism and its application for controlled roof caving in shallow depth seams," International Journal of Rock Mechanics and Mining Sciences, vol. 64, no. 1, pp. 112-121, 2013.

[7] Y. Chen, S. P. Hao, and Y. T. Chen, "Study on the application of short-hole blasting with guide hole to roof cutting pressure relief of gob-side entry retaining," Journal of Mining \& Safety Engineering, vol. 32, no. 2, pp. 253-259, 2015.

[8] D. M. Zhang, X. Bai, and G. Z. Yin, "Mechanism of breaking and fracture expansion of liquid $\mathrm{CO}_{2}$ phase change jet fracturing in low-permeability coal seam," Journal of China Coal Society, vol. 43, no. 11, pp. 3154-3168, 2018.

[9] C. Y. Xu, B. Bai, and M. Z. Liu, "Experimental study of the fracture characteristics of granite under $\mathrm{CO}_{2}$ injection condition," Rock and Soil Mechanics, vol. 40, no. 4, pp. 1474-1483, 2019.

[10] F. Hassock, "Static demolition by calcium oxide," Journal of the Japan Explosives Society, vol. 6, no. 5, pp. 225-232, 2001.

[11] S. Li, Z. J. Li, and M. K. Luo, "Experimental study on reasonable composition andProportion of coal and rock static cracking agent," Blasting, vol. 35, no. 1, pp. 137-153, 2018.

[12] P. Li and G. H. Nie, "Study on the static cracking agent," Journal of Hubei University for Nationalities (Natural Science Edition), vol. 30, no. 2, pp. 159-162, 2012.

[13] X. X. Xu, Research and Application on Expansion Mechanical Behaviors of Static Cracking Agent, Northeastern University, Shenyang, China, 2014.

[14] Y. L. Feng, "Experimental research and apply on the soundless cracking agent," AnHui University of Science and Technology, Huainan, China, 2010.

[15] M. Cai, E. T. Brown, and Brown, "Challenges in the mining and utilization of deep mineral resources," Engineering, vol. 3, no. 4, pp. 432-433, 2017.

[16] P. G. Ranjith, J. Zhao, M. Ju, R. V. S. De Silva, T. D. Rathnaweera, and A. K. M. S. Bandara, "Opportunities and challenges in deep mining: a brief review," Engineering, vol. 3, no. 4, pp. 546-551, 2017.

[17] H. P. Xie, "Research review of the state key research development program of China: deep rock mechanics and mining theory," Journal of China Coal Society, vol. 44, no. 5, pp. 1283-1305, 2019.

[18] M. C. He, H. P. Xie, and S. Q. Peng, "Study on rock mechanics of deep mining," in Proceedings of the Fourth Symposium on Deep Rock Mechanics and Engineering Disaster Control, Beijing, China, 2009.

[19] M. C. He, "Progress and challenges of soft rock engineering in depth," Journal of China Coal Society, vol. 39, no. 8, pp. 1409-1417, 2014.

[20] X. Hao, W. Du, Y. Zhao et al., "Dynamic tensile behaviour and crack propagation of coal under coupled static-dynamic loading," International Journal of Mining Science and Technology, vol. 30, no. 5, pp. 659-668, 2020.

[21] X. Hao, Y. Wei, K. Yang et al., "Anisotropy of crack initiation strength and damage strength of coal reservoirs," Petroleum Exploration and Development, vol. 48, no. 1, pp. 243-255, 2021.

[22] C. Y. Li, Y. Zhang, and J. P. Zuo, "Floor failure mechanical behavior and partition characteristics under the disturbance of voussoir beam instability in deep coal mining," Journal of China Coal Society, vol. 44, no. 5, pp. 1508-1520, 2019.
[23] L. Y. Li, H. P. Xie, and Y. Ju, "Experimental study on the release of strain energy and dissipated energy from rocks," Engineering Mechanics, vol. 28, no. 3, pp. 35-40, 2011.

[24] M. F. Cai, D. Ji, and Q. F. Guo, "Study of rockbust prediction based on in-situ stress measurement and theory of energy accumulation caused by mining disturbance," Chinese Journal of Rock Mechanics and Engineering, vol. 32, no. 10, pp. 1973-1980, 2013.

[25] P. B. Li and J. N. Wang, "Experimental study on mechanical properties of overlying strata in coal seam with variation of occurrence depth," Journal of Harbin Institute of Technology, vol. 47, no. 12, pp. 98-101, 2015.

[26] F. Cui, Y. B. Yang, and X. P. Lai, "Experimental study on the effect of advancing speed and stoping time on the energy release of overburden in an upward mining coal working face with a hard roof," Sustainability, vol. 12, no. 1, p. 37, 2020.

[27] F. Cui, T. Zhang, X. Lai, J. Cao, and P. Shan, "Study on the evolution law of overburden breaking angle under repeated mining and the application of roof pressure relief," Energies, vol. 12, no. 23, pp. 4513-4532, 2019.

[28] F. Cui, S. Dong, X. Lai, J. Chen, J. Cao, and P. Shan, "Study on rule of overburden failure and rock burst hazard under repeated mining in fully mechanized top-coal caving face with hard roof," Energies, vol. 12, no. 24, pp. 4780-4795, 2019. 